\title{
Impact of nasal continuous positive airway pressure treatment on quality of life in patients with obstructive sleep apnoea
}

\author{
J. Bolitschek*, A. Schmeiser-Rieder+, R. Schobersberger ${ }^{+}$, A. Rosenberger+, \\ M. Kunze+ ${ }^{+}$K. Aigner*
}

Impact of nasal continuous positive airway pressure treatment on quality of life in patients with obstructive sleep apnoea. J. Bolitschek, A. Schmeiser-Rieder, R. Schobersberger, A. Rosenberger, M. Kunze, K. Aigner. (CERS Journals Ltd 1998.

ABSTRACT: Quality-of-life (QoL) issues have become increasingly important in health care practice and research. Obstructive sleep apnoea syndrome (OSAS) results in an especially serious reduction in QoL.

The purpose of this study was to measure the QoL (life satisfaction) of OSAS patients treated with nasal continuous positive airway pressure (nCPAP). We aimed to determine whether and to what extent the QoL of OSAS patients using nCPAP differs from that of randomly selected subjects without this disorder.

The QoL of 67 patients treated for at least 3 months with nCPAP, 21 OSAS patients at the time of OSAS diagnosis, and 113 randomly selected persons visiting the hospital (controls) was investigated with the help of the Munich life-quality dimension list (MLDL), an instrument for cognitive assessment of elementary components (physical condition, psyche, social life, everyday life) of QoL.

It was found that QoL of OSAS patients treated with nCPAP did not significantly differ from that of control subjects with regard to elementary components. The 21 untreated OSAS patients showed significantly lower scores in all four subcategories: physical condition $(p<0.0005)$, psyche $(p<0.01)$, social life $(p<0.0005)$ and everyday life $(\mathbf{p}<0.007)$.

Thus, it may be concluded that nasal continuous positive airway pressure therapy has an important impact on the quality of life of obstructive sleep apnoea syndrome patients, and signifies a further advantage in addition to clinical aspects. Treated patients are as satisfied or dissatisfied with their life as persons without this illness. Eur Respir J 1998; 11: 890-894.
*Dept of Lung Diseases, A.ö. Krankenhaus der Elisabethinen, Linz, Austria. +Institute of Social Medicine, University of Vienna, Vienna, Austria.

Correspondence: J. Bolitschek

Dept of Lung Diseases

A.ö. Krankenhaus der Elisabethinen

Fadingerstraße 1

4010 Linz

Austria

Fax: 437327672106

Keywords: Nasal continuous positive airway pressure

obstructive sleep apnoea

quality of life

Received: July 51996

Accepted after revision January 311998
Obstructive sleep apnoea syndrome (OSAS) is a sleeprelated breathing disorder characterized by the occurrence of respiratory arrests during sleep due to upper airway occlusion. Repetitive apnoea and hypopnoea terminated by arousals cause sleep fragmentation and psychological symptoms such as excessive daytime sleepiness (EDS), reduction in intellectual performance and cardiovascular complications with ensuing problems at the place of work and in the family and, at least, a seriously impaired quality of the life (QoL)

QoL issues have become increasingly important in healthcare practice and research [1,2]. An increase in life span or an improvement in laboratory parameters are no longer considered sufficient criteria for the assessment of therapeutic measures. QoL is a multidimensional term, encompassing values that are difficult to define objectively, such as satisfaction, independence, etc. Translating the various domains and components of health into a quantitative value that indicates the $\mathrm{QoL}$ is a complex task. The terms "quality of life" and, more specifically, "health-related quality of life" refer to the physical, psychological and social domains of health, seen as distinct areas that are influenced by a person's experiences, beliefs, expectations and perceptions [1]. The assessment of QoL measures changes in physical functions and mental and social health in order to evaluate human and financial costs and benefits of new programmes and interventions [1].

The majority of studies concerning QoL have been carried out in patients suffering from cancer [2-5], but many specially designed questionnaires have also been used in patients suffering from chronic illnesses such as chronic obstructive pulmonary disease (COPD) [6-8], hypertension and insomnia [9]. Few publications deal with the QoL of patients suffering from OSAS [10-12]. Since its introduction in 1981, nasal continuous positive airway pressure (nCPAP) has been considered an appropriate therapy in cases of severe OSAS. The treatment of OSAS and obstructive snoring improves both the ensuing cardiovascular illness and the mental and psychological problems [13-15]. Data concerning changes in QoL due to nCPAP therapy are scarce $[16,17]$.

The purpose of this study was to measure life satisfaction of OSAS patients treated with nCPAP. We aimed to determine whether and to what extent the QoL of these patients differs from that of randomly selected subjects. 


\section{Methods}

\section{Study population}

Patients treated with nCPAP between November 1988 and February $1995(n=185)$ at the lung department of the Elisabethinen Hospital in Linz, were included in the study. Body mass index (BMI), apnoea/hypopnoea index (AHI), lowest arterial oxygen saturation $\left(\mathrm{Sa}, \mathrm{O}_{2}\right)$, daytime arterial oxygen tension $\left(\mathrm{Pa}_{\mathrm{a}} \mathrm{O}_{2}\right)$ and arterial carbon dioxide tension $\left(\mathrm{Pa}, \mathrm{CO}_{2}\right)$ and mean nCPAP are listed in table 1. Concomitant diseases included hypertension $(21.3 \%)$, COPD (11.0\%), hyperlipidemia $(7.1 \%)$, diabetes mellitus $(1.9 \%)$, Morbus Parkinson (1.3\%), etc.

The patients had undergone treatment with nCPAP for at least 3 months and were still on treatment at the time of this study. The CPAP machines used were REM Star or REM Star Choice (Respironics, Monroeville, Pennsylvania, USA). Patients using bilevel positive airway pressure (BiPAP) and self-titrating CPAP were not included in the study. An AHI >20 was used as an indicator for nCPAP therapy.

Table 1. - Clinical parameters of treated and untreated obstructive sleep apnoea syndrome (OSAS) patients

\begin{tabular}{|c|c|c|c|c|}
\hline & \multicolumn{2}{|c|}{ Treated } & \multicolumn{2}{|c|}{ Untreated } \\
\hline & Mean & SD & Mean & SD \\
\hline BMI $\mathrm{kg} \cdot \mathrm{m}^{-2}$ & 32.87 & 6.99 & 31.61 & 4.55 \\
\hline$P \mathrm{a}, \mathrm{CO}_{2} \mathrm{mmHg}$ & 38.96 & 3.44 & 38.82 & 4.92 \\
\hline$P \mathrm{a}, \mathrm{O}_{2} \mathrm{mmHg}$ & 74.50 & 9.00 & 74.50 & 6.13 \\
\hline Lowest $S_{\mathrm{a}, \mathrm{O}_{2}} \%$ & 70.43 & 11.39 & 74.71 & 7.09 \\
\hline nCPAP $\mathrm{kPa}$ & 1.816 & 0.213 & 0.790 & 0.159 \\
\hline AHI events $\cdot h^{-1}$ & 47.08 & 18.39 & 49.94 & 18.57 \\
\hline Age yrs & 54.47 & 10.03 & 51.55 & 8.24 \\
\hline
\end{tabular}

Treated patients consisted of 100 males (88.5\%), 13 females $(11.5 \%)$ and 42 of unknown sex and age. Untreated patients consisted of 19 males, one female and one of unknown sex. BMI: body mass index; $\mathrm{Pa}_{\mathrm{a}, \mathrm{CO}_{2}}$ : arterial carbon dioxide tension; $\mathrm{Pa}_{\mathrm{a}} \mathrm{O}_{2}$ : arterial oxygen tension; $\mathrm{Sa}_{\mathrm{a}} \mathrm{O}_{2}$ : arterial oxygen satuation; nCPAP: nasal continuous positive airway pressure; AHI: apnoea/hypopnoea index. $1 \mathrm{mmHg}=0.133 \mathrm{kPa}$.
One hundred and thirteen questionnaires were returned in closed envelopes in order to guarantee anonymity. Two patients had died, three had moved and seven questionnaires could not be included in the evaluation because they were returned too late. Thirty four questionnaires were incomplete and were therefore not considered. The present data on QoL are based on 67 questionnaires which were duly filled out and contained no uncertain answers.

The questionnaires were also sent to 21 patients suffering from serious untreated OSAS after the condition had been diagnosed in the sleep laboratory; out of 21 questionnaires, 16 could be evaluated. BMI, AHI, lowest $S \mathrm{a}, \mathrm{O}_{2}$ and daytime $P \mathrm{a}, \mathrm{O}_{2}$ and $P \mathrm{a}, \mathrm{CO}_{2}$, are listed in table 2. Concomitant diseases included hypertension (19.0\%), COPD (14.3\%), hyperlipidemia $(9.6 \%)$, cor pulmonale $(4.8 \%)$, heart failure $(4.8 \%)$, etc. One hundred and seventy eight randomly selected visitors to the hospital served as the control group. The questionnaires were distributed by the receptionists at the hospital. The receptionists were instructed not distribute questionnaires to patients and to make sure they did not hand out more than one questionnaire to one person. The questionnaires were distributed to every person contacting the commissionaire between 14:00 and 16:00 h during visiting hours (on three days), when outpatient departments were closed. The completed questionnaires were deposited in a box at the commissionaire's office.

\section{QoL questionnaire}

For the examination of QoL the "Munich life-quality dimension list" (MLDL) was used. The MLDL is an instrument for cognitive assessment of elementary components of QoL and is a fully standardized procedure for self-evaluation. The authors of MLDL started the item generation with an open survey of a large group of healthy and sick people, concerning their QoL, in order to develop a subjective theory with regard to a definition and utility of QoL. Thus, it was possible to define 19 essential fields,

Table 2. - Dimensions of life saturation of treated obstructive sleep apnoea syndrome patients and controls in comparison to untreated patients

\begin{tabular}{|c|c|c|c|c|c|}
\hline Item & Mean rank & Cases $n$ & Mean rank & Controls $\mathrm{n}$ & $\mathrm{p}$-value \\
\hline Health & 92.85 & 17 & 157.007 & 289 & 0.0036 \\
\hline Body performance & 67.97 & 17 & 157.51 & 287 & 0.0026 \\
\hline Quality of sleep & 67.47 & 16 & 157.74 & 289 & 0.0028 \\
\hline Intellectual performance & 85.62 & 17 & 153.88 & 282 & 0.0033 \\
\hline Personal wellbeing & 81.91 & 17 & 155.65 & 285 & 0.0031 \\
\hline Self esteem & 74.91 & 17 & 152.98 & 279 & 0.0029 \\
\hline Relaxing & 102.81 & 16 & 146.95 & 272 & 0.0063 \\
\hline Success and approval & 87.54 & 14 & 151.01 & 281 & - \\
\hline Support by others & 106.24 & 17 & 151.60 & 280 & 0.0050 \\
\hline Independence & 121.12 & 17 & 153.31 & 285 & - \\
\hline Marriage partnership & 118.44 & 17 & 146.66 & 272 & - \\
\hline Sexuality & 106.24 & 17 & 149.51 & 276 & 0.0071 \\
\hline Family life & 120.35 & 17 & 146.54 & 272 & - \\
\hline Friendships social contacts & 103.72 & 16 & 149.50 & 277 & 0.0056 \\
\hline Occupational situation & 95.97 & 16 & 141.64 & 261 & 0.0045 \\
\hline Financial situation & 102.76 & 17 & 154.41 & 285 & 0.0042 \\
\hline Residential situation & 115.26 & 17 & 155.23 & 288 & - \\
\hline Spare time & 120.71 & 17 & 152.81 & 284 & - \\
\hline Medical therapies & 125.06 & 17 & 152.55 & 284 & - \\
\hline
\end{tabular}

The p-values were corrected by the method of Bonferroni-Holm for multiple comparison. Nonsignificant (Ns) p-values are marked; other p-values were significant. 
which could be divided into four categories: physical condition, psyche, social life and everyday life. These 19 items were presented in our study in the following sequence: health, body performance, quality of sleep (instead of the item "coping with the disease" in the MLDL), intellectual performance, personal wellbeing, self esteem, relaxing, success and approval, support by others, independence, marriage-partnership, sexuality, family life, friendship/social contacts, occupational situation, financial situation, residential situation, spare time and medical treatment. The cognitive assessment of the individual components is carried out on the basis of questions concerning the degree of satisfaction, degree of importance, desire for change and belief in changes which can be brought about in the various areas [18-20].

\section{Statistical analysis}

In order to find differences within all four subareas, "physical condition", "psyche", "social life" and "everyday life", between case and control groups, two-sided t-tests with pooled variance were used. Differences in the scores of the 19 items were examined using Wilcoxon's U-tests. Because of asymmetric distribution, the data were transformed (squared) for analysis using two-sample t-tests.

A check for normal distribution was performed using Kolmogorov-Smirnov tests. The significance level was fix-ed at alpha 0.05 or at corrected alpha levels according to Bonferroni-Holm, respectively. The influencing factors on the QoL were examined by an analysis of variance (ANOVA).

\section{Results}

The QoL of people suffering from OSAS who underwent treatment with nCPAP did not differ from that of people without OSAS, as far as the four subcategories, "physical condition", "psyche", "social life" and "everyday life" were concerned (fig. 1). The 21 untreated OSAS pati-

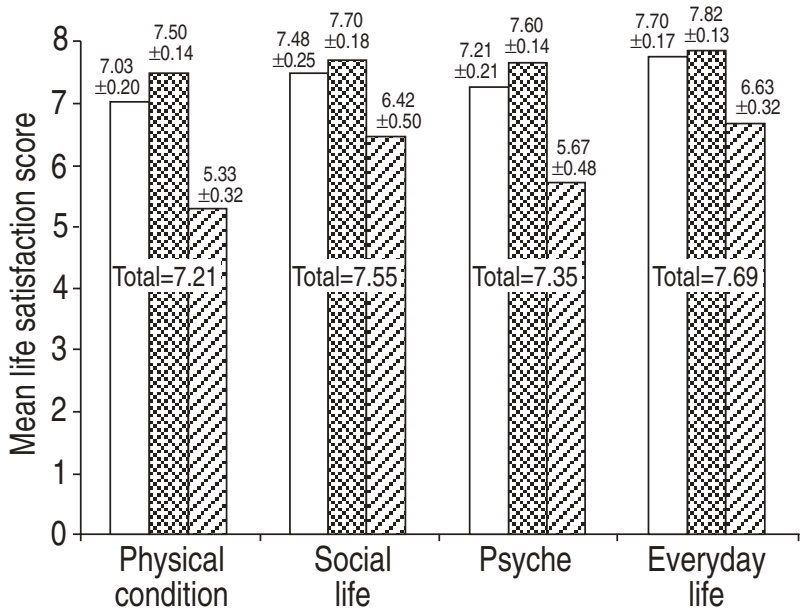

Fig. 1. - Life satisfaction of obstructive sleep apnoea patients treated and untreated with continuous positive airway pressure. $\square$ : treated $(n=67) ; \mathbb{R}:$ control $(n=119) ; Z$ : untreated $(n=12 ; n=16$ for everyday life). Values on the figure are mean \pm sD, and the total for all three groups combined. ents showed significantly lower scores in all four subcategories: physical condition $(\mathrm{p}<0.0005)$, psyche $(\mathrm{p}<0.01)$, social life $(\mathrm{p}<0.0005)$ and everyday life $(\mathrm{p}<0.007)$ (fig. 1$)$. All 19 items of QoL were analysed separately for treated patients and controls; no significant differences were found. The only exception was the item "body performance". Because of these results we assigned treated patients and controls to one group and compared this group with the untreated patients in terms of each item, for which a significant difference was observed (table 2 ). We observed significant differences for the items "health", "body performance", "quality of sleep", "intellectual performance", "personal wellbeing" and "self-esteem". No other items were significantly different. However, there were also differences for the items "support by others" and "financial situation".

All factors influencing satisfaction, such as the level of education, sex, age, marital status, profession, treated sleep apnoea and/or belonging to the control group, were analysed. Marital status turned out to be the only significant influencing factor $(\mathrm{p}<0.001)$.

Widows, divorced persons, or persons living in separation from their spouse showed a considerably lower degree of satisfaction. This result, however, has to be seen in the light of the fact that the number of persons analysed was low $(n=6)$.

The singular comparison between the groups for each item were performed with Wilcoxon U-tests. But doing 19 similar tests, it is easy to find a significant difference for an item just by chance, even if there is none. So it was necessary to correct the reference value for each comparison by the method of Bonferroni-Holm, to keep the family-wise level of significance at alpha $=0.05$. Only items for which the resulting $p$-value was lower than the corrected reference value were classified as showing a significant difference between groups (table 2).

Concerning age, the comparability between controls and OSAS patients is given, although we had a difference of 12 years. This had no influence on the results determined by analysis of variance.

\section{Discussion}

The principal observation of this study was that OSAS patients treated with nCPAP for 3 months or longer showed a very similar QoL to the controls. In other words they were just as satisfied or dissatisfied with their physical condition, social and everyday life and psychic condition as the controls. Patients without treatment had a substantially lower QoL. People in this group were diagnosed shortly before the study or during it.

We used a questionnaire tested in patients with hypertension, diabetes and epilepsy who, in our opinion, are comparable to OSAS patients in terms of risk configuration and impairment of daily life. The MLDL is a fully standardized procedure for self-evaluation. In the literature, an increased tendency to answer questions in terms of "very satisfied" is documented. This tendency was also confirmed in our study. The ensuing asymmetric distribution was "quadrat-transformed" for evaluation. As the question concerning the subjective importance of the individual dimension was not raised, we may assume that all items are of equal importance for each person interviewed. 
A limitation of our study is that we have no information concerning medical data or sleep studies of the controls. Clinical investigation of controls was not planned as we did not intend to compare clinical data of patients with the self-reported morbidity data of controls. Furthermore, a selection bias in case of controls cannot be excluded. However there are no data to show that there was a higher prevalence of OSAS in the controls than in the general population (2-4\%) [21].

The QoL of treated patients at the time of diagnosis is unknown. We assume that their QoL was similar to that of the untreated patients. The effect of nCPAP can only be described by differences and similarity in QoL. Our data do not deliver any information regarding the qualitative and time-related development of QoL and factors influencing the QoL of patients who underwent treatment with nCPAP. Furthermore, we do not suppose that treatment modalities had any influence on QoL, because all patients used CPAP systems of comparable quality and noise. Humidification systems were prescribed only if patients had problems such as a stuffed nose or chronic rhinitis.

In many studies sleepiness has been shown to be one of the greatest and most frequent problems in OSAS (90.2\%) [22], most affecting sustained attention (e.g. long distance driving) and sexual desire [23]. Sleepiness has been shown to improve after nCPAP therapy [24-26]. In all of these studies a single item was examined, but not in the context of QoL. Since there was no question concerning sleepiness in the MLDL, we could not determine to what extent sleepiness affects QoL.

The majority of studies in the literature investigated the QoL of untreated patients [10-12]. We found only two studies dealing with QoL before and after nCPAP therapy. The study of SAPENE et al. [17] was a brief and, at the time of its publication, incomplete investigation. The QoL was assessed with the Nottingham Health Profile (NHP) and depression was evaluated using the centres for Epidemiologic Studies-Depression (CES-D) scale. A comparison before and after 3 months of nCPAP treatment showed a significant improvement in all dimensions of NHP scores, especially energy, mobility and sleep, and also a slight improvement in depressive symptomatology. TOUSIGNANT et al. [16] investigated the number of quality-adjusted life years among 19 OSAS patients using a standard gamble approach. The authors concluded that nCPAP offers a welltolerated therapy with a very favourable cost-utility ratio.

The two above mentioned studies are not directly comparable with ours since different tools were used to assess QoL and the study design was different. However, all three studies demonstrated a positive effect of nCPAP on QoL. In spite of measured total improvement due to treatment, patients may develop specific problems secondary to nCPAP therapy or OSAS, which may not be detected because the QoL questionnaire may not be specific enough.

For this reason there is a demand for a special OSASQoL questionnaire that takes into consideration the specific aspects of this disorder and its treatment.

The nonresponsive rate of $34 \%$ in treated OSAS patients is similar to that registered in other questionnaire studies [27]. On the other hand it may be assumed that the $34 \%$ nonresponders are noncompliant and that the $66 \%$ responders are compliant patients. In a recent study LOJAN-DER et al. [28] found a compliance of $62 \%$ with nCPAP at one year. HoFsTEIN [27] investigated nCPAP compliance by using mailed questionnaires and observed a compliance rate of $81 \%$ in responders and only $62 \%$ in nonres-ponders.

In conclusion, our results suggest that obstructive sleep apnoea syndrome patients who undergo treatment are just as satisfied or dissatisfied with their physical condition, social and everyday life and psychic condition, as are people without this illness.

\section{References}

1. Testa MA, Simonson DC. Assessment of quality-of-life outcomes. N Engl J Med 1996; 334: 835-840.

2. Aaronson NK. Assessing the quality of life of patients in cancer clinical trials: common problems and common sense solution. Eur J Cancer 1992; 28A: 1304-1307.

3. Muthny FA. Zur Messung von Lebensqualität in der Onkologie. Onkologie 1994; 17: 547-556.

4. Ferguson RJ, Cull A. Quality of life measurement for patients undergoing treatment for lung cancer. Thorax 1991; 46(9): 671-675.

5. Ganz PA, Lee JJ, Siau J. Quality of life assessment. An independent prognostic variable for survival in lung cancer. Cancer 1991; 67(12): 3131-3135.

6. Elliott MW, Simonds AK, Caroll MP, Wedzicha JA, Branthwaite MA. Domiciliary nocturnal nasal intermittent positive pressure ventilation in hypercapnic respiratory failure due to chronic obstructive lung disease: effects on sleep and quality of life. Thorax 1992; 47: 342-348.

7. Jones PW. Issues concerning health-related quality of life in COPD. Chest 1995; 107 (Suppl. 5): 187-193.

8. Kaptein AA, Brand PL, Dekker FW, Kerstjens HA, Postma DS, Sluiter HJ. Quality of life in a long-term multicenter trial in chronic nonspecific lung disease: assessment at baseline. The Dutch CNSLD Study Group. Eur Respir J 1993; 6: Suppl. 10, 1479-1484.

9. Rombaut N, Maillard F, Kelly F, Hindmarch I. The quality of life of insomniac questionnaire. Med Sci Res 1990; 18: 845-847.

10. Gall R, Isaac L, Kryger M. Quality of life in mild obstructive sleep apnea. Sleep 1993; 16 (Suppl. 8): 58-61.

11. Bacque ME, Dazord A, Masse E, de Carmoy GR, Fleury B. Measurement of quality of life in obstructive sleep apnea syndrome. Am J Respir Crit Care Med 1995; 151: A748.

12. Bes A, Aran X, Gea J, Orozco-Levi M, Felez MA, Broquetas JM. Somnolence, quality of life in snorers, with and without sleep apnea syndrome. Am J Respir Crit Care Med 1996; 153: A353.

13. Berry RB, Block AJ. Positive nasal airway pressure eliminates snoring as well as obstructive sleep apnea. Chest 1985; 1: 15-20.

14. Engelman HM, Chesire KE, Deary IJ, Douglas NJ. Daytime sleepiness, cognitive performance and mood after continuous positive airway pressure for the sleep apnea/ hypoventilation syndrome. Thorax 1993; 48: 911-914.

15. Montplasire MA, Bedard MA, Richter F, Rouleau I. Neurobehavioral manifestations in obstructive sleep apnea syndrome before and after treatment with continuous positive airway pressure. Sleep 1992; 15: 17-19.

16. Tousignant P, Cosio MG, Levy RD, Groome PA. Quality adjusted life years added by treatment of obstructive sleep apnea. Sleep 1994; 17(1): 52-60.

17. Sapene M, Nejjari C, Tessier JF, Haran P. Evaluation of quality of life and depressive symptomatology of patients 
with sleep apnea syndrome after treatment by continuous positive airway pressure. Am J Respir Crit Care Med 1996; 153: A353.

18. Heinisch M, Ludwig M, Bullinger M. Psychometrische Testung der Münchner Lebensqualitätsfragebogen. In: Bullinger M, Ludwig M, von Steinbüchel N, eds. Lebensqualität bei Cardiovaskulären Erkrankungen, Grundlagen, Meßverfahren, Ergebnisse, Dimensionen Liste (MLDL). 1991; pp. 73-90.

19. Bullinger M, Kirchberger I, Steinbüchel N von. Der Fragebogen Alltagsleben-ein Verfahren zur Messung der gesundheitsbezogenen Lebensqualität. Zeitschrift Medizinischen Pychologie 1993; 3: 121-131.

20. Ludwig M. Lebensqualität auf der Basis subjektiver Theoriebildung. In: Bullinger M, Ludwig M, von Steinbüchel $\mathrm{N}$, eds. Lebensqualität bei Cardiovaskulären Erkrankungen, Grundlagen, Meßverfahren, Ergebnisse, Dimensionen Liste (MLDL) 1991; pp. 23-34.

21. Young T, Palta M, Demsey J. The occurence of sleep-disordered breathing among middle aged adults. $N$ Engl $J$ Med 1993; 328: 1230-1235.

22. Roth T, Roehrs TA, Conway WA. Behavioral morbidity of apnea. Semin Res Med 1988; 9(6): 554-559.
23. Weaver T, Maislin G, Smith P, et al. Determining the functional impact of sleepiness from sleep disordered breathing. Am J Respir Crit Care Med 1995; 151 (4): A748.

24. Sforza E, Lugaresi E. Daytime sleepiness and nasal continuous positive airway pressure therapy in obstructive sleep apnea syndrome: effect of chronic treatment and 1-night therapy withdrawal. Sleep 1995; 18 (3): 195201.

25. Lamphere J, Roehrs T, Wittig R, Zorick F, Conway WA, Roth T. Recovery of alertness after CPAP in apnea. Chest 1989; 96: 1364-1367.

26. Hardinge M, Pitson D, Stradling J. Use of Epworth Sleepiness Scale to demonstrate response to treatment with nCPAP in patients with obstructive sleep apnea. Am J Respir Crit Care Med 1995; 151(4): A749.

27. Hoffstein V, Viner S, Mateika S, Conway J. Treatment of obstructive sleep apnea with continuous positive airway pressure. Am Rev Respir Dis 1992; 145: 841-845.

28. Lojander J, Maasilta P, Partinen M, Brander PE, Salmi T, Lethonen H. Nasal-CPAP, surgery, and conservative management of obstructive sleep apnea syndrome. Chest 1996; 110: 114-119. 